\title{
Detection of Epstein-Barr virus and Kaposi's sarcoma-associated herpesvirus DNA in CSF from persons infected with HIV who had neurological disease
}

\author{
N S Brink, Y Sharvell, M R Howard, J D Fox, M J G Harrison, R F Miller
}

\section{Department of Virology, Division of Pathology and Infectious Diseases, University College London Hospitals NHS Trust and University College London Medical School, London, UK \\ N S Brink \\ Y Sharvell \\ M R Howard \\ J D Fox}

Department of Sexually Transmitted Diseases, Division of Pathology and Infectious Diseases, University College London Medical School and Camden and Islington Community Health Services NHS Trust, London, UK R F Miller

\section{Department of} Neurology, University College London Medical School, London, UK

M J G Harrison

Correspondence to: Dr NS Brink, Department of Virology, University College London Hospitals NHS Trust, Windeyer Building, 46 Cleveland Street, London W1P 6DB, UK.

Received 8 August 1997 and in revised form 13 January 1998

Accepted 30 January 1998

\begin{abstract}
Objectives-To determine the frequency and clinical relevance of Epstein-Barr virus (EBV) and Kaposi's sarcoma associated herpesvirus (KSHV) DNA detection in the CSF from patients infected with HIV.

Methods-Cerebrospinal fluid was obtained prospectively from 115 consecutive patients infected with HIV undergoing diagnostic lumbar puncture for investigation of neurological disease. Amplification of DNA was performed using a nested polymerase chain reaction (PCR) for detection of EBV internal repeat and KSHV minor capsid sequences.

Results-EBV DNA was detected in the CSF supernatant of 18 patients. This included all patients with primary CNS lymphoma (seven patients) or a combination of systemic and CNS lymphoma (two patients). By contrast EBV DNA was not detected in the CSF supernatant of any patient with systemic, but not CNS, lymphoma (10 patients). EBV DNA was also detected in the supernatant of nine further patients without a diagnosis of lymphoma at the time of lumbar puncture, two of whom subsequently developed CNS lymphoma. No EBV DNA was detected in CSF supernatant from the remaining 87 samples (two of these patients subsequently developed lymphoma). KSHV DNA was detected in the CSF of two patients, one had systemic (but not CNS) lymphoma and the other did not have lymphoma.
\end{abstract}

Conclusion-A diagnosis of CNS lymphoma is strongly associated with the presence of EBV DNA in CSF. In the absence of clinical and radiological features of CNS lymphoma, the presence of detectable CSF EBV DNA may predict subsequent tumour development. KSHV DNA is rarely detected in CSF in this patient group and shows no correlation with lymphoma or other neurological disease.

(F Neurol Neurosurg Psychiatry 1998;65:191-195)

Keywords: lymphoma; AIDS; CSF; Epstein-Barr virus; Kaposi's sarcoma associated herpesvirus; DNA detection

Epstein-Barr virus (EBV) has been associated with some lymphoproliferative disorders in the immunocompromised patient. ${ }^{1}$ In particular EBV DNA has been detected in tumour tissue of virtually all AIDS related CNS lymphoma ${ }^{23}$ and in about $50 \%$ of patients with AIDS related systemic lymphoma. ${ }^{4}$ Histological confirmation of the diagnosis of primary CNS lymphoma in a patient infected with HIV may be difficult; some patients may be considered too unwell to undergo brain biopsy and in others the lesions may be located at an anatomically inaccessible site. Attempts have therefore been made to identify other markers of primary CNS lymphoma. Retrospective studies have shown that $83 \%-97 \%$ of patients with HIV with a primary CNS lymphoma have detectable EBV DNA in CSF. ${ }^{56}$ Although this provides clinically useful information and may obviate the need for brain biopsy, questions have been raised about the relevance of a positive result in the absence of neuroradiological features of lymphoma.?

Kaposi's sarcoma is a common AIDS defining illness in patients with HIV. Recently DNA from a novel herpesvirus, now known as Kaposi's sarcoma associated herpesvirus (KSHV), has been detected in Kaposi's sarcoma tumour tissue $^{8}$ and tumour tissue taken from patients with body cavity based lymphomas. ${ }^{9}$ The full range of clinical disease associated with this newly described herpesvirus remains, however, to be defined.

The aim of this prospective study was to determine the frequency and clinical relevance of EBV and KSHV DNA detection in CSF taken from patients with HIV undergoing diagnostic lumbar puncture for investigation of neurological disease and to correlate these results with the final clinical diagnosis in this group of patients.

\section{Patients and methods}

PATIENTS

Cerebrospinal fluid was obtained prospectively from 115 consecutive patients with HIV (108 men and seven women) admitted to the HIV/AIDS Inpatient Unit, University College London Hospitals between March 1993 to November 1995. All patients were admitted for investigation of neurological disease. Six patients had more than one CSF sample taken (two samples in five patients and three samples in one). This study was performed within the guidelines of the Middlesex Hospital clinical investigations panel.

Patients were divided into two groups on the basis of whether, at the time of lumbar 
Table 1 Correlation between CSF polymerase chain reaction (PCR) results for the detection of Esptein-Barr virus (EBV) and Kaposi's sarcoma-associated herpesvirus (KSHV) DNA and clinical manifestations in 115 patients infected with HIV

\begin{tabular}{|c|c|c|c|c|c|}
\hline \multirow[b]{2}{*}{ Diagnosis } & \multirow[b]{2}{*}{$\begin{array}{l}\text { Patients } \\
\text { (n) }\end{array}$} & \multicolumn{2}{|c|}{$\begin{array}{l}\text { EBV DNA in CSF } \\
\text { (supernatant) }\end{array}$} & \multicolumn{2}{|c|}{$\begin{array}{l}\text { KSHV DNA in CSF } \\
\text { (pellet) }\end{array}$} \\
\hline & & Detected & $\begin{array}{l}\text { Not } \\
\text { Detected }\end{array}$ & Detected & $\begin{array}{l}\text { Not } \\
\text { Detected }\end{array}$ \\
\hline \multicolumn{6}{|l|}{ Lymphoma: } \\
\hline Cerebral & 7 & 7 & 0 & 0 & 5 \\
\hline Cerebral and systemic & 2 & 2 & 0 & 0 & 1 \\
\hline Systemic & 10 & 0 & 10 & 1 & 6 \\
\hline Total & 19 & 9 & 10 & 1 & 12 \\
\hline \multicolumn{6}{|l|}{ Other neurological conditions: } \\
\hline HADC & 27 & 1 & 26 & 0 & 9 \\
\hline Cryptococcal meningitis & 17 & 0 & 17 & 0 & 1 \\
\hline CMV encephalitis (one also had CMV polyradiculopathy) & 13 & 2 & 11 & 0 & 3 \\
\hline CMV retinitis (two also had CMV polyradiculopathy) & 7 & 3 & 4 & 1 & 2 \\
\hline Self limiting headache & 6 & 1 & 5 & 0 & 3 \\
\hline Toxoplasmosis & 3 & 1 & 2 & 0 & 1 \\
\hline Mononeuneuritis multiplex & 2 & 0 & 2 & 0 & 0 \\
\hline Transient ischaemic attack & 2 & 0 & 2 & 0 & 0 \\
\hline Sepsis, or confusional state & 2 & 0 & 2 & 0 & 1 \\
\hline Isolated cranial nerve palsy & 2 & 0 & 2 & 0 & 0 \\
\hline Acute retinal necrosis & 2 & 0 & 2 & 0 & 0 \\
\hline Disseminated MAI infection & 2 & 0 & 2 & 0 & 0 \\
\hline TB meningitis & 1 & 1 & 0 & 0 & 1 \\
\hline Myelopathy & 1 & 0 & 1 & 0 & 1 \\
\hline Miscellaneous conditions & 9 & 0 & 9 & 0 & 0 \\
\hline Total & 96 & 9 & 87 & 1 & 22 \\
\hline
\end{tabular}

HADC = HIV associated dementia complex $; \mathrm{CMV}=$ cytomegalovirus $; \mathrm{MAI}=$ Mycobacterium avium-intracellulare $; \mathrm{TB}=$ Mycobacterium tuberculosis.

Miscellaneous conditions includes a single case each of sinusitis, prolapsed intervertebral disc, postviral encephalitis, idiopathic epilepsy, viral encephalitis (aetiology undetermined), disseminated Hodgkin's disease, disseminated extraneural cryptococcosis, and cerebellar astrocytoma.

puncture, they had lymphoma (either CNS, systemic, or a combination of both) or an alternative diagnosis (table 1 ). In 17 patients the diagnosis of lymphoma was made by histological analysis of tissue obtained at biopsy (11 patients; two also had postmortem confirmation) or postmortem (five patients). In a further three patients, all of whom had refused brain biopsy, the diagnosis was made on the basis of typical appearances on $\mathrm{MRI}^{10}$ together with typical thallium-201 scan appearances (one patient). ${ }^{11}$

Protein and glucose concentrations in CSF were determined and the presence or absence of a CSF pleocytosis was noted. The CSF was stained histochemically and cultured for bacteria, mycobacteria, and fungi and assayed for antibodies to Treponema pallidum and Cryptococcus neoformans antigen. An aliquot of CSF was analysed for the presence of EBV DNA. In a subset of 36 patients sufficient CSF remained to enable analysis for the presence of KSHV DNA to be performed.

NESTED POLYMERASE CHAIN REACTION AMPLIFICATION

The nested polymerase chain reaction (PCR) method and oligonucleotide primers used for the detection of EBV internal repeat and KSHV minor capsid sequences have been described. ${ }^{12}{ }^{13}$ For EBV the CSF samples were pelleted (15000 g, 5 minutes); the supernatant was boiled for 10 minutes and cooled on ice, and then $10 \mu \mathrm{l}$ was added directly to the first round mixture. We have shown previously that centrifugation at $15000 \mathrm{~g}$ is sufficient to avoid cellular contamination of the CSF as human DNA sequences (pyruvate dehydrogenase) cannot be detected using a sensitive nested PCR. ${ }^{14}$ In 24 patients, seven of whom had sys- temic (but not CNS) lymphoma, and 17 of whom had an alternative diagnosis, the CSF cell pellet was also analysed by nested PCR amplification for EBV DNA. For KSHV DNA detection (on a subset of 36 patients) both CSF cell pellet and supernatant liquid were analysed. The supernatant was processed as for EBV DNA detection, DNA was extracted from the cell pellet using $20 \mu \mathrm{l}$ extraction buffer containing $10 \mathrm{mM}$ TRIS, $5 \mathrm{mM} \mathrm{KC1,} 2.5 \mathrm{mM}$ $\mathrm{MgCl}_{2}, 0.5 \% \mathrm{NP} 40,0.5 \%$ Tween 20 , and 50 $\mu \mathrm{g} / \mathrm{ml}$ proteinase $\mathrm{K}$ and incubated for 2 hours at $56^{\circ} \mathrm{C}$. Extracted DNA $(10 \mu \mathrm{l})$ was added to the first round of PCR.

Any obviously contaminated blood samples were treated as described above, but were also examined for inhibition of nested PCR by titration of dilutions of the positive control in aliquots of these samples. The sensitivity of each PCR was assessed using tissue culture derived virus (EBV) and purified KSHV DNA (prepared in house), each of which was diluted in pooled CSF that did not contain detectable herpesvirus DNA. It is estimated that 10 or less copies of EBV and two to five copies of KSHV DNA could be detected after two rounds of nested PCR. Reaction conditions and cycling indices were unchanged from those previously described $^{1213}$ and the products of PCR were examined by ethidium bromide gel electrophoresis. Appropriate positive and negative controls were included in each PCR run: pooled herpesvirus negative CSF, distilled water, and the equivalent of 10 and 100 copies of EBV and KSHV DNA.

End point titration was used to determine EBV viral load in a subset of eight patients, four with a primary CNS lymphoma, one with a 
Table 2 Alternative diagnoses, follow up, and outcome in nine patients with no lymphoma at the time of EBV DNA detection in CSF supernatant

\begin{tabular}{|c|c|c|c|c|c|}
\hline $\begin{array}{l}\text { Patient } \\
\text { No }\end{array}$ & Alternative clinical diagnosis & Cranial MRI & $\begin{array}{l}\text { Follow up } \\
\text { (weeks) }\end{array}$ & Necropsy & Cause of death \\
\hline 1 & CMV retinitis, cutaneous K.S & No focal lesion & 107 & Yes & Primary CNS lymphoma \\
\hline 2 & CMV retinitis and CMV radioculopathy & No focal lesion & 19 & Yes & Primary CNS lymphoma \\
\hline 3 & HADC & No focal lesion & 62 & No & HADC, HIV wasting \\
\hline 4 & Cerebral toxoplasmosis & Multiple ring enhancing lesions & 60 & No & HIV wasting \\
\hline 5 & Self limiting headache & No focal lesion & 13 & No & HIV wasting, disseminated KS \\
\hline 6 & $\begin{array}{l}\text { CMV retinitis and } \\
\text { CMV encephalitis }\end{array}$ & No focal lesion & 4 & No & $\begin{array}{l}\text { CMV encephalitis } \\
\text { HIV wasting }\end{array}$ \\
\hline 7 & Tuberculous meningitis & No focal lesion & 3 & No & Tuberculous meningitis \\
\hline 8 & $\begin{array}{l}\text { CMV retinitis } \\
\text { CMV encephalitis }\end{array}$ & No focal lesion & 2 & No & CMV encephalitis \\
\hline 9 & CMV retinitis confusion due to pneumonia & No focal lesion & 1 & No & Bacterial pneumonia, disseminated KS, HIV wasting \\
\hline
\end{tabular}

$\mathrm{CMV}=$ cytomegalovirus; HADC=HIV associated dementia complex; KS=Kaposi's sarcoma.

combination of systemic and CNS lymphoma, and three with alternative neurological diagnoses.

STATISTICAL ANALYSIS

Results were compared using a two tailed Fisher's exact test. Values with $\mathrm{p}<0.05$ was considered significant.

\section{Results}

EBV DNA DETECTION IN CSF SUPERNATANT

Epstein-Barr virus DNA was detected in the CSF supernatant of 18 patients. This included all patients with primary CNS lymphoma (seven patients) and all those with both CNS and systemic lymphoma (two patients). By contrast EBV DNA was not detected in the CSF of any patient with systemic but not CNS lymphoma (10 patients) (table 1 ).

Nine patients without a diagnosis of lymphoma at the time of lumbar puncture had detectable EBV DNA in the CSF supernatant, two of whom subsequently developed CNS lymphoma confirmed at necropsy 19 and 107 weeks later (table 2). The remaining seven patients with detectable EBV DNA in CSF supernatant but without a diagnosis of CNS lymphoma at the time of lumbar puncture all died between 1 and 62 weeks after their original lumbar puncture-none developed clinical or radiological features of lymphoma before death (table 2). Of the 96 patients without detectable EBV DNA in CSF supernatant and with alternative diagnoses (table 1), two subsequently developed CNS lymphoma, 13 and 40 weeks later, diagnosed on the basis of typical MRI and thallium-201 appearances and failure of response to antitoxoplasma therapy. Necropsy in a further 14 of these 96 patients confirmed the absence of CNS and systemic lymphoma.

REPEAT EPISODES

Six patients had repeat CSF sampling. One patient had CNS lymphoma with blast cells and EBV DNA in CSF supernatant. After cranial radiotherapy he presented again 20 weeks later with cytomegalovirus polyradiculopathy; Cytomegalovirus and EBV DNA were detected in CSF supernatant. Necropsy confirmed CNS lymphoma. Another patient (No 3, table 2) had HIV associated dementia complex (HADC), EBV DNA was detected in CSF supernatant. He underwent repeat lumbar puncture 4 and 16 weeks later because of pro- gressive decline in cognitive function, the CSF supernatant on neither occasion contained detectable EBV DNA. Two further patients had cryptococcal meningitis; they were sampled again by lumber puncture 47 and 26 weeks later when the diagnosis was respectively relapse of cryptococcal meningitis and cytomegalovirus retinitis with septicaemia. The fifth patient had HADC; he presented again 32 weeks later with cerebral toxoplasmosis, which responded to specific treatment. The final patient had acute retinal necrosis due to varicella zoster virus infection; he presented again 27 weeks later with a toxic confusional state. EBV DNA was not detected in CSF supernatant from any of the samples from these four patients.

EBV DNA DETECTION IN CSF CELL PELLET

Three patients had detectable EBV DNA in the cellular pellet but not the CSF supernatant. One subsequently developed CNS and systemic lymphoma, confirmed at necropsy 15 weeks later, one had systemic lymphoma at the time of lumbar puncture and one remains alive at 133 weeks with severe HADC but no clinical evidence of lymphoma.

KSHV DNA DETECTION

KSHV DNA was not detected in the CSF supernatant from any of the 36 samples (13 patients with lymphoma and 23 with alternative diagnoses, table 1). However, KSHV DNA was detected in the CSF cellular pellet from two patients, one with systemic lymphoma but without CNS lymphoma and no evidence of Kaposi's sarcoma and the other with cytomegalovirus retinitis, no lymphoma, but widespread cutaneous Kaposi's sarcoma. This second patient also had detectable EBV DNA in the CSF supernatant and subsequently developed CNS lymphoma (patient 1, table 2).

Counts for CD4 lymphocytes were available in all patients; The median CD4 count for patients with lymphoma was $0.06 \times 10^{9} / 1$; normal range $0.35-2.2 \times 10^{9} / 1$ ) and for those with alternative diagnoses it was $0.02 \times 10^{9} / 1$ (range $\left.0-0.31 \times 10^{9} / 1\right)$. In all but one patient with lymphoma the white blood cell count in CSF ranged from $0-20$ cells $/ \mathrm{mm}^{3}$ (12 patients had no white cells in the CSF). There was evidence of a CSF pleocytosis in one patient (264 cells $\mathrm{mm}^{3}$ ); this person had a concomitant cytomegalovirus polyradiculopathy.

There was a significant association between detectable EBV DNA in CSF supernatant and 
Table 3 End point titration with nested PCR for detection of EBV DNA in CSF supernatant of patients with lymphoma and other diagnoses

\begin{tabular}{ll}
\hline & $\begin{array}{l}\text { Detectable copies of } \\
\text { EBV DNA/ } \mu \text { CSF } \\
\text { supernatant }\end{array}$ \\
Diagnosis & 10 \\
\hline Cerebral lymphoma & 1000 \\
Cerebral lymphoma & 1000 \\
Cerebral lymphoma & 10000 \\
Cerebral lymphoma & 1000 \\
Cerebral and systemic lymphoma & $<10$ \\
Cerebral toxoplasmosis & 10 \\
Self limiting headache $\dagger$ & 10000 \\
CMV retinitis/CMV encephalitis $\ddagger$ & \\
\hline
\end{tabular}

^Patient 4 ; tpatient 5 ; łpatient 6 ; as shown in table 2 .

the diagnosis of primary CNS lymphoma or a combination of CNS and systemic lymphoma compared with patients with systemic (but not CNS) lymphoma ( $<0.0001$; two tailed Fisher's exact test).

Semiquantification of CSF EBV DNA was carried out on a subset of eight patients using end point titration. The results are shown in table 3. There was no apparent difference in the viral load of patients with and without lymphoma. Of the three patients who did not have lymphoma, the highest EBV DNA load was seen in a patient (No 6, table 2) with cytomegalovirus retinitis and encephalitis who died 4 weeks later from progressive encephalitis and HIV wasting syndrome, without clinical evidence of lymphoma.

\section{Discussion}

In this prospective study 115 patients with HIV were investigated for the presence of detectable EBV DNA in CSF. Patients were classified into those with a diagnosis of lymphoma and those with an alternative diagnosis. There was a significant association between detectable EBV DNA in the CSF supernatant and both primary CNS lymphoma and cerebral involvement by disseminated systemic lymphoma. By contrast EBV DNA was not detected in CSF supernatant of patients with disseminated systemic lymphoma who did not have CNS involvement.

A study of 83 patients with HIV who had CSF obtained within 180 days of death and necropsy showed that all 17 cases of primary CNS lymphoma had detectable EBV DNA using nested PCR and EBV DNA was detected in only one of 68 patients with an alternative diagnosis. ${ }^{6}$ No EBV DNA was detected in the CSF of two patients with a disseminated systemic lymphoma and with CNS involvement, a finding which contrasts with ours. In a further study of 500 patients infected with HIV 36 had primary CNS lymphoma confirmed by necropsy; 35 of these had detectable CSF EBV DNA. ${ }^{7}$ These studies, together with ours, confirm that detection of EBV DNA in CSF is strongly associated with primary CNS lymphoma and may obviate the need for brain biopsy in those patients with clinical and radiological features of lymphoma. However, it may not be possible to perform a lumbar puncture in all patients with suspected cerebral lymphoma as the presence of a mass lesion on neuroradiological imaging may be a contrain- dication. Detection of CSF EBV DNA therefore, forms part of the diagnostic investigation of an immunosuppressed patient with an intracerebral mass lesion - the precise application will depend on the individual patient's clinical and neuroradiological features.

The clinical relevance of detectable EBV DNA in CSF in the absence of features consistent with a diagnosis of CNS lymphoma needs careful evaluation. In this study a minority (nine of 96) of patients without clinical or radiological features of lymphoma had detectable EBV DNA in CSF supernatant; two of these patients subsequently developed lymphoma. This suggests that the detection of EBV DNA in CSF from patients with HIV without lymphoma may predict subsequent tumour development. Such patients should be considered as at possible risk of developing lymphoma and promptly investigated if clinically indicated. However, results must be interpreted with caution as we showed transient detection of EBV DNA in the CSF of one patient. In addition, a further two patients without detectable CSF EBV DNA subsequently developed cerebral lymphoma. The absence of detectable CSF EBV DNA does, however, play a critical part in the evaluation of a focal CNS lesion in an immunosuppressed patient, as this strongly suggests an alternative diagnosis.

As nested PCR is a very sensitive technique, the clinical relevance of a positive result needs careful interpretation. A potential area of concern is contamination of CSF with virus from mononuclear cells in peripheral blood resulting in detectable EBV DNA in CSF arising from EBV DNA contained in these cells. This is important as it has been shown, using nested PCR, that mononuclear cells in peripheral blood from $61 \%$ of patients with HIV with low CD4 lymphocyte counts contain detectable EBV DNA. ${ }^{13}$ Contamination of CSF by such cells is unlikely in this study as cell free supernatant was examined. In addition, there was a significant association between detectable CSF EBV DNA and a diagnosis of CNS lymphoma. A potential concern about the use of cell free supernatant is a reduction in diagnostic sensitivity. For this reason we examined the CSF cell pellet on a subset of patients. However, all of the patients with CNS lymphoma in this study had detectable EBV DNA in CSF supernatant, indicating the suitability of this CSF fraction for analysis in patients with suspected CNS lymphoma.

We examined the EBV DNA load in CSF in a subset of patients, both with and without lymphoma at the time of lumbar puncture (table 3). Although the number analysed were too small to allow definitive comment, there was no apparent difference in the viral load of patients with and without lymphoma. This finding needs further investigation with the inclusion of larger sample numbers.

As the clinical disease range of infection with KSHV remains to be precisely defined, the possible association of infection with this virus and neurological disease in patients with HIV was examined in a subset of 36 patients. No 
association between detectable KSHV DNA and neurological disease-in particular lymphoma-was noted in this small group.

Detection of EBV DNA in the CSF of patients with HIV is strongly associated with primary CNS lymphoma as well as cerebral involvement from disseminated systemic lymphoma. However, EBV DNA may be detected in the CSF of patients without clinical or radiological features of lymphoma-this may predict for subsequent tumour development. No association between detectable KSHV DNA in CSF and neurological disease was noted in this group of patients with HIV.

We thank Professor Dorothy Crawford for helpful discussions There is no conflict of interest.

1 Hanto DW, Frizzera G, Purtilo DT, et al. Clinical spectrum of lymhoproliferative disorders in renal transplant patients and evidence of the role of Espstein-Barr virus. Cancer Res 1981;41:4253-61.

2 MacMahon EME, Glass JD, Hayward SD, et al. EpsteinMacMahon EME, Glass JD, Hayward SD, et al. Epstein-
Barr virus in AIDS-related primary cerebral lymphoma.

3 Pednaultt E, Katz BS, Miller G. Detection of Epstein-Barr virus in the brain by the polymerase chain reaction. Ann Neurol 1992;32:184-92.

4 Hamilton-Dutoit SJ, Raphael M, Andouin J, et al. In situ demonstration of Epstein-Barr virus small RNAs (EBER 1) in acquired immunodeficiency-related lymphomas: correlation with tumour morphology and primary site. Blood 1993;82:619-24.
5 Arribas JR, Clifford DB, Fichtenbaum CJ, et al. Detection of Epstein-Barr virus DNA in cerebrospinal fluid for diagnosis of AIDS-related central nervous system lymphoma. $\mathcal{F}$ Clin Microbiol 1995;33:1580-3.

6 Cinque $\mathrm{P}$, Brytting $\mathrm{M}$, Vago L, et al. Epstein-Barr virus DNA in cerebrospinal fluid from patients with AIDSrelated primary lymphoma of the central nervous system. Lancet 1993;342:398-401.

7 Cinque P, Vago L, Dahl H, et al. Polymerase chain reaction on cerebrospinal fluid for diagnosis of virus-associaited opportunistic diseases of the central nervous system in opportunistic diseases of the central nervo
HIV-infected patients. AIDS 1996;10:951-8.

8 Chang Y, Cesarman E, Pessin MS, et al. Identification of herpesvirus-like DNA sequences in AIDS-associated Kaposi's sarcoma. Science 1994;266:1865-9.

9 Cesarman E, Chang Y, Moore PS, et al. Kaposi's sarcoma associated herpesvirus-like DNA sequences in AIDSrelated body-cavity-based lymphomas. N Engl f Med 1995; 332:1186-91.

10 Cordoliani Y-S, Derosier C, Pharaboz C, et al. Primary cerebral lymphoma in patients with AIDS: MR findings in 17 cases. AfR Am f Roentgenol 1992;159:841-7.

11 Lorberboym M, Estok L, Machac J, et al. Rapid differential diagnosis of cerebral toxoplasmosis and primary central nervous system lymphoma by thallium-201 SPECT. $7 \mathrm{Nucl}$ Med 1996;37:1150-4.

12 Wakefield AJ, Fox JD, Sawyer AM, et al. Detection of herpesvirus DNA in large intestine of patients with ulcerative colitis and Crohn's disease using the nested polymerase chain reaction. F Virol Methods 1992;38:183-90.

13 Whitby D, Howard MR, Tenant-Flowers M, et al. Detection of Kaposi's sarcoma associated herpesvirus in peripheral blood of HIV-infected individuals and progression to Kaposi's sarcoma. Lancet 1995;346:799-802.

14 Fox JD, Brink NS, Zuckerman MA, et al. Detection of herpesvirus DNA by nested polymerase chain reaction in cerebrospinal fluid of human immunodeficiency virusinfected persons with neurologic disease: a prospective evaluation. F Infect Dis 1995;172:1087-90. 